\title{
Mental Health Impact of COVID-19 Pandemic on Health Care Workers in Ebonyi State, Southeast, \\ Nigeria
}

\author{
Okechukwu B. Anozie ${ }^{* 1,2}$, Johnbosco I. Nwafor ${ }^{1}$, Ephraim I. Nwokporo ${ }^{3}$, Chidi U. Esike ${ }^{1,2}$, Richard L. Ewah ${ }^{4,5}$, \\ Justus N. Eze ${ }^{1,2}$, Benedict N. Azuogu ${ }^{6,7}$, Chukwuemeka I. Ukaegbe ${ }^{1,2}$ \\ ${ }^{1}$ Department of Obstetrics and Gynaecology, Alex Ekwueme Federal University Teaching Hospital, Abakaliki, \\ Ebonyi State, Nigeria \\ ${ }^{2}$ Department of Obstetrics and Gynaecology, Ebonyi State University, Abakaliki, Ebonyi State, Nigeria \\ ${ }^{3}$ Department of Sociology, Alex Ekwueme Federal University Ndufu-Alike, Ikwo, Ebonyi State, Nigeria \\ ${ }^{4}$ Department of Anasthesia, Alex Ekwueme Federal University Teaching Hospital, Abakaliki, Ebonyi State, Nigeria \\ ${ }^{5}$ Department of Anasthesia, Ebonyi State University, Abakaliki, Ebonyi State, Nigeria \\ ${ }^{6}$ Department of Community Medicine, Alex Ekwueme Federal University Teaching Hospital, Abakaliki, Ebonyi \\ State, Nigeria \\ ${ }^{7}$ Department of Community Medicine, Ebonyi State University, Abakaliki, Ebonyi State, Nigeria
}

*Corresponding Author: Dr. Okechukwu B. Anozie; okeyanoziey2k@yahoo.com

Received 24 August 2020;

Accepted 03 September 2020;

Published 16 September 2020

\begin{abstract}
Background: Globally, mental health issues have become one of the predominant public health concerns as a result of the COVID-19 outbreak. The impact of COVID-19 pandemic on the mental health of frontline healthcare workers has not been fully described in Nigeria. Aim: To determine the mental health impact of COVID-19 pandemic and its associated factors among frontline healthcare workers in Ebonyi State, Nigeria. Materials and methods: This was an online cross-sectional study conducted among 315 frontline healthcare workers treating COVID19 patients at Alex Ekwueme Federal University Teaching Hospital, Abakaliki, Ebonyi State, Nigeria. The mental health outcome of the participants was assessed using the short form of the Mental Health Continuum (MHC-SF). Results: The prevalence of mental health outcome for different categories was $47 \%(\mathrm{n}=148)$ for flourishing, $28.3 \%(\mathrm{n}=89)$ for moderate and $24.7 \%(\mathrm{n}=78)$ for languishing mental health. The predictors of languishing mental health outcome were being married $(\mathrm{OR}=3.12,95 \% \mathrm{CI} 1.67-4.09, \mathrm{p}=0.035)$, a physician $(\mathrm{OR}=4.09,95 \% \mathrm{CI}$ $1.98-5.61, \mathrm{p}=0.002)$, a nurse $(\mathrm{OR}=2.21,95 \% \mathrm{CI} 0.05-0.24, \mathrm{p}<0.001)$, limited access to personal protective equipment $(\mathrm{OR}=3.25,95 \% \mathrm{CI}$ $1.62-6.22, \mathrm{p}=0.043)$ and self-isolation and quarantine due to SARS-CoV-2 infection $(\mathrm{OR}=3.03,95 \% \mathrm{CI} 0.02-0.95, \mathrm{p}<0.001)$. Conclusion: Nigeria's frontline healthcare workers, especially physicians and nurses, are experiencing COVID-19 related psychological distress. There is need to develop and implement interventions to reduce the impact of prolonged psychological distress on long-term mental wellbeing in healthcare workers treating COVID-19 patients.
\end{abstract}

Keywords: Mental health outcome, COVID-19 pandemic, Healthcare workers, Nigeria

\section{Introduction}

The impact of COVID-19 is ubiquitous to all cohorts of the society but its mental health impact is most felt by healthcare workers (HCWs) especially those in the frontline ${ }^{[1]}$. Globally, mental health issues have become one of the predominant public health concerns as a result of the COVID-19 outbreak. It has affected the ability of most HCWs to combat everyday life stressors ${ }^{[2]}$. The high risk of exposure, increased workload, shortage of personal protective equipment, anxiety of getting infected, antisocial behavior from patients, conditions requiring ethically difficult decisions on the rationing of care and fear of spreading the virus to family and friends all compound to cause mental health issues for most HCWs ${ }^{[3]}$. Casualties (deaths) recorded by HCWs during the Ebola and other disease outbreaks in Nigeria cannot help but elevate causes for worry among HCWs and their families. Studies have found social/physical distancing, self-isolation and quarantine measures used in curbing the spread of COVID-19 to cause considerably mental health issues ${ }^{[4]}$. Consequently, mental health issues like severe fatigue, stress, sleep disturbance, depression, 
anxiety, phobia and trauma has been on the increase among HCWs $[5,6]$

Healthcare workers such as doctors, nurses, laboratory scientists and nursing technicians especially those in direct contact with COVID-19 patients and/or their body fluids are vulnerable to developing psychological symptoms during and in post COVID-19 [7]. Lee found $18 \%$ to $57 \%$ of health professionals to have experienced mental health issues during and after the Severe Acute Respiratory Syndrome (SARS) outbreak in $2003{ }^{[8]}$. Other Studies on the SARS outbreak also reported acute stress reactions from HCWs ${ }^{[9]}$. At the wake of COVID-19 outbreak in China, HCWs had recorded depression, anxiety and insomnia respectively ${ }^{[10,11]}$. Mental health implications of pandemics like COVID-19 are likely to result into a persistent mental issue for most HCWs ${ }^{[12,13]}$. The high contagious rate of COVID-19 may also result to stigma for HCWs by other population group with little or no exposure risk to COVID-19 ${ }^{[14,15]}$. In late July, 2020 Nigeria had recorded 36,663 confirmed cases of COVID-19 with 789 deaths. Ebonyi State became the $13^{\text {th }}$ state with the highest confirmed cases (655) with about 14 deaths ${ }^{[16]}$. The unprecedented mental health impact of the COVID-19 pandemic in Nigeria is yet to be established hence, the need of this research. This study therefore aims at evaluating the mental health impact of COVID-19 on frontline HCWs in Ebonyi State, Nigeria.

\section{Materials and Methods}

\section{Study design, period and area}

This was an online questionnaire-based cross-sectional study conducted between June 1, 2020 and July 31, 2020 among healthcare workers at Alex Ekwueme Federal University Teaching Hospital, Abakaliki, Ebonyi State, Nigeria. Approval for the study was obtained from the Research and Ethics Committee of the Alex Ekwueme Federal University Teaching Hospital, Abakaliki.

\section{Study population}

The study participants were healthcare workers, including doctors, nurses, allied healthcare workers(pharmacists, physiotherapists, occupational therapists), administrators, clerical staff and maintenance workers who are directly or indirectly involved in the care of COVID-19 patients in Ebonyi State, Nigeria.

\section{Study criteria}

All healthcare workers who gave informed consent to participant in the study were included in the study. Those who declined to participate were excluded from the study.

\section{Sample size calculation}

The sample size was calculated by taking the population of 315 healthcare workers who are directly or indirectly involved in the care of COVID-19 patients as source population. The minimum sample size at $95 \%$ confidence interval was calculated as 260 by using Open Epi software package version 3.01 ${ }^{[17]}$ with an anticipated frequency of $50 \%$, a design effect of 1.5 and error margin of $5 \%$. Allowing for a $10 \%$ dropout rate for unpredictable events, the final required sample size was calculated as 286 .
However, 315 healthcare workers involved in the care of COVID19 patients participated in the study.

\section{Data collection instrument}

An anonymous questionnaire using Google Forms was used to collect data. Link to the online form were shared through emails and social media platforms like WhatsApp and Telegram. The study questionnaire, written in English, comprised three main components - demographic characteristics, experiences of healthcare workers treating COVID-19 patients and prevalence in the previous month, flourishing, moderate and languishing mental health using the short form of the Mental Health Continuum (MHC-SF) ${ }^{[18]}$

Baseline demographic characteristics such as gender, age, marital status, occupation, length of work experience and COVID19 infection status were recorded. We also collected a series of information about experiences during care of COVID-19 patients.

Mental health outcome was assessed using MHC-SF, which is a validated screening instrument for use among patients and general populations ${ }^{[19]}$. It consists of 14 items representing the construct definition for each facet of well-being. Three items (happy, interested in life, and satisfied) represent emotional wellbeing, six items (one item from each of the 6 dimensions) represent psychological well-being, and five items (one item from each of the 5 dimensions) represent social well-being. The response option for the short form measures the frequency with which respondents experienced each symptom of positive mental health, and thereby provided a clear standard for the assessment and a categorization of levels of positive mental health that was similar to the standard used to assess and diagnosis major depressive episode. To be diagnosed with flourishing mental health, individuals must experience 'every day' or 'almost everyday' at least one of the three signs of hedonic well-being and at least six of the eleven signs of positive functioning during the past month. Individuals who exhibit low levels (i.e., 'never' or 'once or twice' during the past month) on at least one measure of hedonic well-being and low levels on at least six measures of positive functioning are diagnosed with languishing mental health. Individuals who are neither flourishing nor languishing are diagnosed with moderate mental health.

\section{Statistical analysis}

The collected data were analysed using SPSS version 22 (IBM Corp. Amork, New York, U.S.A). Categorical variables are expressed as absolute values (percentage) and continuous variables were expressed as mean value \pm standard deviation. The prevalence of mental health categories; flourishing, moderate and languishing mental health, was reported. Multivariable logistic regression was employed to evaluate for associations between baseline characteristics and mental health outcome categories of the participants. The results of the multivariate regression analysis were expressed as odds ratio (OR) at $95 \%$ confidence interval, with level of significance set at $\mathrm{p}<0.05$.

\section{Results}

Table 1: Socio-demographic characteristics of the participants

\begin{tabular}{lcc}
\hline Socio-demographic characteristics & Frequency & Percentage \\
\hline Sex & & \\
\hline Male & 142 & 45.1 \\
Female & 173 & 54.9 \\
\hline Age range & & \\
\hline 18 - 2 yrs & 11 & 3.5
\end{tabular}




\begin{tabular}{lll}
25 - 34yrs & 156 & 49.5 \\
$35-44$ yrs & 113 & 35.9 \\
$45-54$ yrs & 31 & 9.8 \\
55 - 64yrs & 4 & 1.3 \\
\hline Marital status & & \\
\hline Single & 116 & 36.8 \\
Married without child & 26 & 8.3 \\
Married with one child & 25 & 7.9 \\
Married with more than one children & 133 & 42.2 \\
Divorced & 9 & 2.9 \\
Widowed & 6 & 1.9 \\
\hline Occupation & & \\
\hline Physician & 197 & 62.5 \\
Nurse & 54 & 17.1 \\
Allied Health Care Professional & 25 & 7.9 \\
Technician & 13 & 4.1 \\
Clerical staff & 7 & 2.2 \\
Administrator & 16 & 5.1 \\
Maintenance worker & 3 & 1.0 \\
\hline Length of work experience & & \\
\hline Less than 3 years & 16 & 33.7 \\
4 - 10 years & 106 & 34.9 \\
11 - 20years & 110 & 21.9 \\
21 - 30years & 69 & 6.7 \\
31 above & 21 & 2.9 \\
\hline
\end{tabular}

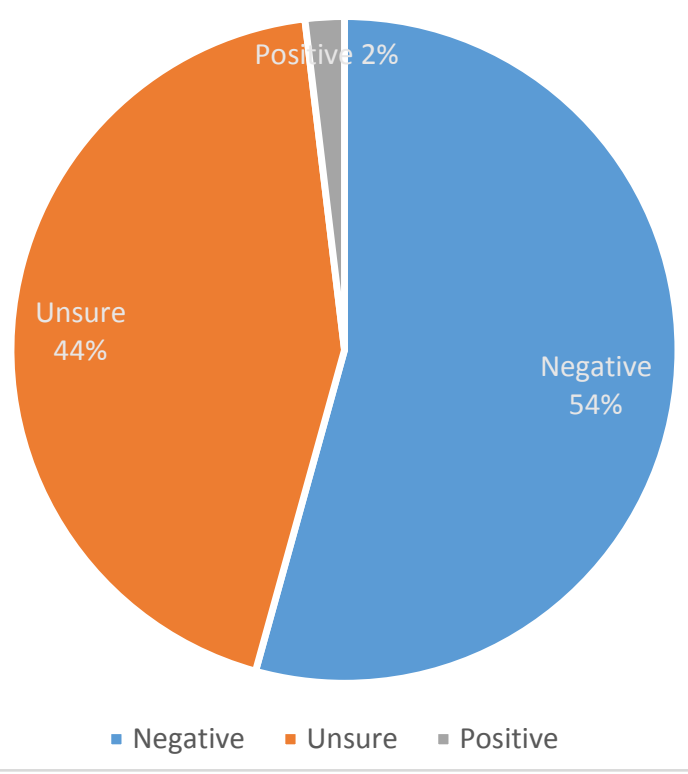

Figure 1: Chart showing COVID-19 infection status of the participants

Table 2: Experiences of the participants during care of COVID-19 infected patients

\begin{tabular}{lll}
\hline Items & Frequency & Percentage \\
\hline Limited access to PPE & 248 & 78.7 \\
\hline Yes & 67 & 21.3 \\
No & & \\
Reason of limited access & 70 & 28.2 \\
Poor supply & 1 & 0.4 \\
Hording by staff & 36 & 14.5 \\
Poor hospital administration & & \\
Experienced prolong working hour & 170 & 54.0 \\
\hline Yes & 145 & 46.0 \\
No & & \\
\hline
\end{tabular}




\begin{tabular}{|c|c|c|}
\hline Items & Frequency & Percentage \\
\hline \multicolumn{3}{|l|}{ Often times } \\
\hline Every day & 33 & 19.4 \\
\hline More than once in a week & 29 & 17.1 \\
\hline Almost everyday & 21 & 12.4 \\
\hline Few times in a month & 7 & 4.1 \\
\hline Rarely & 16 & 9.4 \\
\hline \multicolumn{3}{|c|}{ Experienced conditions requiring ethically difficult decision on the rationing of care } \\
\hline Yes & 94 & 29.8 \\
\hline No & 221 & 70.2 \\
\hline \multicolumn{3}{|l|}{ Often times } \\
\hline More than once a month & 4 & 4.3 \\
\hline More than once a week & 15 & 16.0 \\
\hline Sometimes & 8 & 8.5 \\
\hline Occasionally & 15 & 16.0 \\
\hline \multicolumn{3}{|c|}{ Experienced antisocial behavior from COVID 19 patients } \\
\hline Yes & 35 & 11.1 \\
\hline No & 280 & 88.9 \\
\hline \multicolumn{3}{|l|}{ Reason for the experience } \\
\hline Every time & 12 & 34.3 \\
\hline Occasionally & 4 & 11.4 \\
\hline \multicolumn{3}{|c|}{ Self-isolation and quarantine measures can cause considerably mental health issues } \\
\hline Yes & 203 & 64.4 \\
\hline No & 112 & 35.6 \\
\hline \multicolumn{3}{|l|}{ Reason } \\
\hline Feeling of separation & 11 & 5.4 \\
\hline Stigmatization & 14 & 6.9 \\
\hline Depression & 70 & 34.5 \\
\hline Psychological trauma & 4 & 2.0 \\
\hline Anxiety & 3 & 4.4 \\
\hline \multicolumn{3}{|c|}{ Lack of COVID-19 Testing Kit in the hospital } \\
\hline Yes & 196 & 62.2 \\
\hline No & 119 & 37.8 \\
\hline \multicolumn{3}{|l|}{ Reason } \\
\hline Poor administration & 14 & 7.6 \\
\hline Inadequate supply & 19 & 10.3 \\
\hline
\end{tabular}

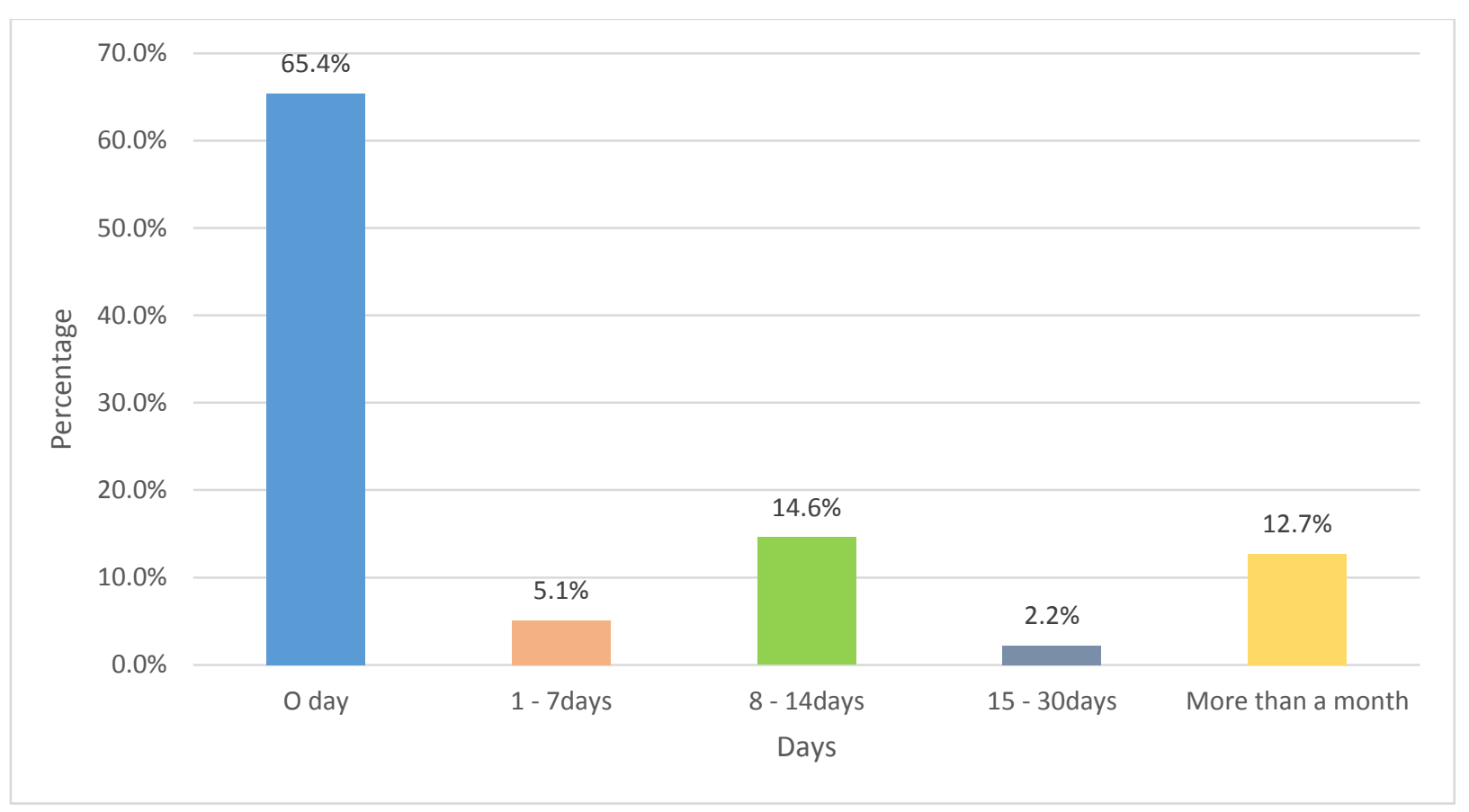

Figure2: Chart showing length of been away from family to avoid bring COVID-19 home 
Table 3: Multivariate logistic regression analysis of variables related to mental health outcome $(\mathrm{N}=315)$

\begin{tabular}{|c|c|c|c|c|c|c|}
\hline \multirow{3}{*}{ Variable } & \multicolumn{6}{|c|}{ Categorical diagnosis } \\
\hline & \multicolumn{2}{|c|}{ Flourishing $(\mathrm{n}=148)$} & \multicolumn{2}{|c|}{ Moderate (n=89) } & \multicolumn{2}{|c|}{ Languishing $(\mathrm{n}=78)$} \\
\hline & OR(95\%CI) & p-value & OR(95\%CI) & p-value & OR(95\%CI) & p-value \\
\hline \multicolumn{7}{|l|}{ Gender } \\
\hline Male & 1.00 & & 1.00 & & 1.00 & \\
\hline Female & $1.23(0.98-1.54)$ & 0.236 & $0.97(0.43-1.51)$ & 0.612 & $3.02(0.08-0.32)$ & 0.022 \\
\hline Age (years) & $0.15(1.33-3.51)$ & 0.219 & $1.12(0.62-2.11)$ & 0.065 & $0.98(0.66-2.77)$ & 0.248 \\
\hline \multicolumn{7}{|l|}{ Marital status } \\
\hline Single & 1.00 & & 1.00 & & 1.00 & \\
\hline Married & $2.61(0.05-0.142)$ & 0.001 & $1.95(0.76-2.23)$ & 0.059 & $3.12(1.67-4.09)$ & 0.035 \\
\hline \multicolumn{7}{|l|}{ Divorced $^{\mathrm{a}}$} \\
\hline \multicolumn{7}{|l|}{ Widowed $^{\mathrm{a}}$} \\
\hline \multicolumn{7}{|l|}{ Occupation } \\
\hline Administrator & 1.00 & & 1.00 & & 1.00 & \\
\hline Physician & $2.09(0.03-1.01)$ & 0.056 & $1.69(0.87-1.36)$ & 0.089 & $4.09(1.98-5.61)$ & 0.002 \\
\hline Nurse & $1.80(0.23-2.17)$ & 0.061 & $1.76(0.22-4.12)$ & 0.087 & $2.21(0.05-0.24)$ & $<0.001$ \\
\hline Allied health care professional & $0.88(0.43-1.54)$ & 0.954 & $1.15(0.66-1.51)$ & 0.231 & $1.16(0.17-1.92)$ & 0.985 \\
\hline Technician & $1.05(0.67-1.39)$ & 0.271 & $0.65(0.12-1.84)$ & 0.517 & $0.83(0.25-4.11)$ & 0.519 \\
\hline \multicolumn{7}{|l|}{ Clerical staff $\mathrm{a}^{\mathrm{a}}$} \\
\hline \multicolumn{7}{|l|}{ Length of work experience (years) } \\
\hline$<3$ & 1.00 & & 1.00 & & 1.00 & \\
\hline $4-10$ & $3.51(0.08-0.71)$ & $<0.001$ & $0.28(0.92-5.65)$ & 0.062 & $1.09(0.22-3.62)$ & $0.279)$ \\
\hline $11-20$ & $0.14(0.26-4.02)$ & 0.515 & $2.29(0.01-0.63)$ & 0.024 & $0.53(0.26-1.85)$ & 0.655 \\
\hline $21-30$ & $1.01(0.53-4.12)$ & 0.713 & $0.71(0.91-1.68)$ & 0.329 & $2.31(1.44-6.21)$ & 0.003 \\
\hline \multicolumn{7}{|l|}{$\geq 31^{\mathrm{a}}$} \\
\hline \multicolumn{7}{|l|}{ Limited access to PPE } \\
\hline No & 1.00 & & 1.00 & & 1.00 & \\
\hline Yes & $1.83(0.93-3.38)$ & 0.573 & $0.65(0.38-3.39)$ & 0.763 & $3.25(1.62-6.22)$ & 0.043 \\
\hline \multicolumn{7}{|c|}{ Experienced prolong working hour } \\
\hline No & 1.00 & & 1.00 & & 1.00 & \\
\hline Yes & $0.91(0.26-1.72)$ & 0.438 & $1.07(0.24-4.33)$ & 0.099 & $1.29(0.08-2.07)$ & 0.067 \\
\hline
\end{tabular}

Experienced conditions requiring

ethically difficult decision on the

rationing of care

\begin{tabular}{|c|c|c|c|c|c|c|}
\hline No & 1.00 & & 1.00 & & 1.00 & \\
\hline Yes & $1.883(0.09-3.22)$ & 0.075 & $0.54(0.37-1.19)$ & 0.758 & $1.57(0.56-6.75)$ & 0.247 \\
\hline \multicolumn{7}{|c|}{ Experienced antisocial behavior from } \\
\hline \multicolumn{7}{|c|}{ COVID 19 patients } \\
\hline No & 1.00 & & 1.00 & & 1.00 & \\
\hline Yes & $0.16(0.18-5.23)$ & 0.363 & $0.86(0.41-6.22)$ & 0.543 & $1.60(0.29-4.51)$ & 0.083 \\
\hline
\end{tabular}

Self-isolation and quarantine due to

COVID-19

\begin{tabular}{lllllll}
\hline No & 1.00 & & 1.00 & & 1.00 & \\
Yes & $0.49(0.21-4.03)$ & 0.089 & $0.15(0.53-6.81)$ & 0.106 & $3.03(0.02-0.95)$ & $<0.001$ \\
\hline
\end{tabular}

Abbreviation: PPE; personal protective equipment, ${ }^{a}$ data not sufficient for logistic regression analysis.

A total of 315 healthcare workers participated in the study. The mean age of the participants was $28.4 \pm 8.9$ years. The majority of the participants were female (54.9\%), married $(58.4 \%)$, physicians $(62.5 \%)$ and had between $4-10$ years experience in their occupation (34.9\%) (Table 1). Of 315 participants, $2 \%$ tested positive to SARS-CoV-2 infection, whereas $54 \%$ tested negative for the virus (figure 1).

Table 3 shows the experiences of the participants during the care of COVID-19 infected patients in the treatment centre. $78.7 \%$ of the participants reported limited access to personal protective equipment (PPE) and the commonest reason was short supply (28.2\%). Just over half (54\%) of the participants reported working for longer hour every day whereas $29.8 \%$ reported experiencing conditions requiring ethically difficult decision on the rationing of care. Participants' reported experience of antisocial behaviour from SARS-CoV-2 patients occurred in $11.1 \%$ of the participants. Nearly two-thirds $(64.4 \%)$ of the participants agreed that self-isolation and quarantine measures can cause considerably mental health issues and commonest reason (34.5\%) was due to depression associated with it. 196 (62.2\%) participants thought that COVID-19 testing kit was lacking in the hospital and this was due to shortage of supply $(10.3 \%)$. 
Figure 2 shows length of time the participants were away from family to avoid infecting family members with SARS-CoV-2. About two-thirds (65.4\%) of the participants reported not staying away from family, $14.6 \%$ stayed away from home for 8 - 14 days and $12.7 \%$ avoided home for more than a month to prevent infecting family members with SARS-CoV-2.

The prevalence of mental health outcome for different categories, assessed using MHC-SF, was 47\% ( $\mathrm{n}=148)$ for flourishing mental health, $28.3 \%(\mathrm{n}=89)$ for moderate mental health and $24.7 \%(\mathrm{n}=78)$ for languishing mental health (table 3$)$.

Multivariate logistic regression analysis of variables associated with mental health outcomes is shown in table 3 . The determinants of flourishing mental health among healthcare workers involved in the care of COVID-19 patients were being married $(\mathrm{OR}=2.61,95 \% \mathrm{CI} 0.05-0.142, \mathrm{p}=0.001)$ and work experience of $4-10$ years $(\mathrm{OR}=3.51,95 \% \mathrm{CI} 0.08-0.71, \mathrm{p}<$ $0.001)$. Apart from work experience of $11-20$ years $(\mathrm{OR}=2.29$, $95 \% \mathrm{CI} 0.01-0.63, \mathrm{p}=0.024)$, no other variables were significantly associated with moderate mental health outcome among the participants. Various socio-demographic characteristics were associated with languishing mental health outcome among the participants. Gender was associated with languishing mental health outcome. Female healthcare providers $(\mathrm{OR}=3.02$, 95\%CI 0.08 $0.32, \mathrm{p}=0.022$ ) were 3 times more likely to be categorised as languishing when compared with males. Also marital status had a significant association with languishing mental health outcome. Married participants $(\mathrm{OR}=3.12,95 \%$ CI $1.67-4.09, \mathrm{p}=0.035)$ were 3 times at higher risk of developing languishing mental health outcome when compared to unmarried participants. Other independent predictor variables significantly associated with developing languishing mental health outcome were being a physician $(\mathrm{OR}=4.09,95 \% \mathrm{CI} 1.98-5.61, \mathrm{p}=0.002)$, a nurse (OR $=2.21,95 \%$ CI $0.05-0.24, \mathrm{p}<0.001)$, having work experience of $21-30$ years $(\mathrm{OR}=2.31,95 \% \mathrm{CI} 1.44-6.21, \mathrm{p}=0.03)$, and limited access to PPE (OR $=3.25$, 95\%CI $1.62-6.22, \mathrm{p}=0.043)$. Selfisolation and quarantine due to SARS-CoV-2 infection was a significant predictor of languishing mental health outcome. Participants who self-isolated and quarantined $(\mathrm{OR}=3.03,95 \% \mathrm{CI}$ $0.02-0.95, \mathrm{p}<0.001)$ were 3 times more likely to develop languishing mental health outcome when compared with those who did not.

\section{Discussion}

Studies from SARS or Ebola epidemics showed that the onset of a sudden and immediately life-threatening illness could lead to increased pressure on healthcare workers (HCWs), which can lead to adverse physical and mental health ${ }^{[8,9]}$. This could be attributed to increased workload, physical exhaustion, inadequate personal equipment, nosocomial transmission, and the need to make ethically difficult decisions on the rationing of care. Their resilience to cope with increased pressure can be further compromised by isolation and loss of social support, risk or infections of friends and relatives as well as drastic, often unsettling changes in the ways of working. HCWs are, therefore, especially vulnerable to mental health problems, including fear, anxiety, depression and insomnia ${ }^{[20]}$.

Our cross sectional survey results show that self-reported psychological problems are prevalent in healthcare workers during the COVID-19 pandemic. Healthcare workers exhibited a distinct prevalence of flourishing, moderate and languishing mental health. The high prevalence of languishing mental health outcome (24.7\%) that was found in this study is consistent with recent findings from studies done in other countries ${ }^{[1,2,4]}$. A study done in China showed severe mental health conditions in healthcare workers and indicated that medical health workers reported more symptoms compared with non-medical health workers ${ }^{[11]}$. In addition, compared with the general population, healthcare workers have a much higher risk of psychological problems during the pandemic. This may be related to the higher risk of infection on account of being exposed to patients with COVID-19 and tedious work involved in caring for them and reminds us of the importance of providing psychological support to healthcare workers during a pandemic.

In this study, marital status had a significant association with languishing mental health outcome. Married participants (OR $=3.12,95 \%$ CI $1.67-4.09, \mathrm{p}=0.035$ ) were 3 times at higher risk of developing languishing mental health state when compared to unmarried participants. This is not surprising as the fear of transmitting the virus to family members and friends has been reported in other studies as contributing to adverse psychological outcome for frontline workers during the COVID-19 pandemic ${ }^{[11,20]}$. In addition, limited access to PPE and self-isolation and quarantine for testing positive to SARS-CoV-2 were risk factors for languishing mental health outcome among the study participants. These findings were similar to that of other works in many countries ${ }^{[1,11,20]}$.

Although the psychological impact of COVID-19 pandemic is taking its toll on healthcare workers, physicians and nurses were particularly affected. The different responsibilities of physicians and nurses may partly explain the higher rates of languishing mental health among them, as they are spending more time delivering direct patient care. In the context of COVID-19, those responsibilities increase the likelihood of vicarious traumatization, including having to provide direct social support or emotional labor for patients in place of patients' family who are not allowed inside the hospital due to transmission concerns. Although languishing mental health are normal and expected during traumatic events, and symptoms are expected to decline for many who currently screen positive for this category, a substantial proportion are likely to subsequently meet diagnostic criteria for posttraumatic stress disorder ${ }^{[21]}$.

Although this was a cross-sectional study, adverse mental health state can last longer than the pandemic period. A 1-year follow up study conducted during the 2003 SARS outbreak comparing healthcare workers with high-risk and low-risk exposure, showed that healthcare workers from hospitals treating SARS patients had higher levels of distress and PTSD compared to healthcare workers from matched neighboring hospitals that did not treat SARS patients ${ }^{[22]}$. Therefore, there is need for long term psychological support for frontline workers caring for SARS-CoV2 infected patients so as to avert prolonged adverse mental health outcome.

The strength of this study is that it is the first comprehensive study of mental health outcome among frontline healthcare workers treating patients with COVID-19 in Abakaliki, Nigeria. The limitation of the study is that it did not assess current coping behaviors and the types of wellness resources, such as stress reduction activities, especially physical activity/exercise, talk therapy, virtual support groups, and religious/spiritual practices, that participants might find useful.

In conclusion, this study shows that the participants are experiencing significant distress with $24.7 \%$ screening positive to languishing mental health category. The outcome of this study should inform the basis for the development and implementation of interventions to reduce the impact of prolonged psychological 
distress on long-term mental wellbeing in healthcare workers treating COVID-19 patients.

\section{Conflict of interest}

Authors declare no conflict of interest

\section{Acknowledgement}

None

\section{References}

[1] Ahorsu DK, Lin CY, Imani V, Saffari M, Griffiths MD, Pakpour AH. The fear of COVID-19 scale: Development and initial validation. Inter $\mathrm{J}$ Mental Health Addiction. https://doi.org/10.1007/s11469-020-00270-8.

[2] Shanafelt T, Ripp J, Trockel M. Understanding and addressing sources of anxiety among health care professionals during the COVID-19 pandemic. JAMA $2020 . \quad$ https://doi.org/10.1001/jama.2020.5893. [Published Online First: 2020/04/08].

[3] Cao W, Fang Z, Hou G, Han M, Xu X, Dong J, et al. The psychological impact of the COVID-19 epidemic on college students in China. Psychiatry Research, 2020; 287: e112934.

[4] Ho CS, Chee CY, Ho RC. Mental health strategies to combat the psychological impact of COVID-19 beyond paranoia and panic. Annals Acad Med Singapore, 2020; 49: $1-3$.

[5] Sakib N, Mamun MA, Bhuiyan AI, Hossain S, Al Mamun F, Hosen I, et al. Psychometric validation of the Bangla fear of COVID-19 scale: confirmatory factor analysis and Rasch analysis. Int J Mental Health Addiction 2020 https://doi.org/10.1007/s11469-02000289-x.

[6] Suseela V. Psychological issues based on gender and marital status during COVID-19 lockdown period. Tathapi 2020, 19(8):755-764.

[7] Pappa S, Ntella V, Giannakas T, Giannakoulis VG, Papoutsi E, Katsaounou P. Prevalence of depression, anxiety, and insomnia among healthcare workers during the COVID-19 pandemic: a systematic review and metaanalysis. Brain, Behavior and Immunity. https://doi.org/10.1016/j.bbi.2020.05.026.

[8] Lee SM, Kang WS, Cho AR, Kim T, Park JK. Psychological impact of the 2015 MERS outbreak on hospital workers and quarantined hemodialysis patients. Compr Psychiatry 2018; 87:123-7.

[9] Tam CW, Pang EP, Lam LC, Chiu HF. Severe acute respiratory syndrome (SARS) in Hong Kong in 2003: stress and psychological impact among frontline healthcare workers. Psychol Med 2004; 34 (7): 11971204.
[10] Rossi R, Socci V, Pacitti F, Di Lorenzo G, Di Marco A, Siracusano A, et al. Mental health outcomes among front and second line health workers associated with the COVID-19 pandemic in Italy. medRxiv.04.16.20067801 [Preprint]. 2020.

[11] Lai J, Ma S, Wang Y, et al. Factors Associated With Mental Health Outcomes Among Health Care Workers Exposed to Coronavirus Disease 2019. JAMA Netw Open 2020; 3:e203976.32202646

[12] Li Z, Ge J, Yang M, Feng J, Qiao M, Jiang R, et al. Vicarious traumatization in the general public, members, and non-members of medical teams aiding in COVID-19 control. Brain Behav Immun 2020; [Epub ahead of print].

[13] Ornell F, Schuch JB, Sordi AO, Kessler FHP. "Pandemic fear" and COVID-19: mental health burden and strategies. Braz J Psychiatry 2020; [Epub ahead of print].

[14] Khan KS, Mamun MA, Griffiths MD, Ullah I. The Mental Health Impact of the COVID-19 Pandemic across Different Cohorts. Int J Mental Health Addiction 2020. https://doi.org/10.1007/s11469-020-00367-0.

[15] Mukhtar S. Pakistanis' mental health during the COVID19. Asian J Psychiatry 2020; 51:102-127. https://doi.org/10.1016/j.ajp.2020.102127

[16] Nigeria Centre for Disease Control. An update of COVID-19 outbreak in Nigeria. 2020. https://ncdc.gov.ng/diseases/sitreps/?cat $=\&$ nam $=$ An $\% 20$ update $\% 20$ of $\% 20$ COVID19\%20outbreak\%20in\%20Nigeria. Accessed July 31, 2020.

[17] Dean AG, Sullivan KM, Soe MM. OpenEpi: Open Source Epidemiologic Statistics for Public Health, Version. Updated 2013. www.OpenEpi.com. Accessed May 28, 2020.

[18] Keyes CLM. The mental health continuum: From languishing to flourishing in life. $J$ Health Social Behavior; 2002 43: 207-222.

[19] Lamers SMA, Westerhof GJ, Bohlmeijer ET Evaluating the psychometric properties of the Mental Health Continuum-Short Form (MHC-SF) J Clin Psychol 2011; 67:99-110.

[20] Shechter A, Diaz F, Moise N, Anstey DE, Ye S, Agarwal $\mathrm{S}$, et al. Psychological distress, coping behaviors, and preferences for support among New York healthcare workers during the COVID-19 pandemic. General Hospital Psychiatry, 2020; 66:1-8.

[21] Nwafor JI, Obi VO, Obi CN, Ibo CC, Ugoji DPC, Onwe $\mathrm{BI}$, et al. Mental health outcome and perceived care needs of women treated for a miscarriage in a lowresource setting. Trop J Obstet Gynaecol 2020;37:85-94.

[22] Maunder RG, Lancee WJ, Balderson KE. Long-term psychological and occupational effects of providing hospital healthcare during SARS outbreak. Emerg Infect Dis 2006; 12(12):1924-32. https://doi.org/10.3201/eid1212.060584. [Published Online First: 2007/03/01]. 